Kalpa Publications in Computing
Volume 12, 2019, Pages 157-168
Proceedings of 4th International Conference on the
Internet, Cyber Security and Information Systems 2019

\title{
Adoption of Business Intelligence in the South African public social sector Department
}

\author{
Hosiah Masha $^{1}$ Dr. Samuel Adeyelure ${ }^{1}$ and Prof Osden Jokonya ${ }^{2}$ \\ ${ }^{1}$ Tshwane University of Technology, Pretoria. RSA \\ ${ }^{2}$ University of North West, Mafikeng. RSA \\ Hosiah2000@gmail.com, adeyelureTSetut.ac.za, Jokonyao@hotmail.com
}

\begin{abstract}
Social Sector department is expected to transform socio economic stands of the poor through technology by digitising service delivery processes in order to enhance decision making, however this has created lot of silo systems with large volumes of data to be manipulated and used. Business Intelligence is seen as supporting technology required to deal with the problem but the sector does not have a model or a framework to adopt the technology. Hence this study intended to develop a model for adoption of Business Intelligence in the South African public social sector Department. Two theoretical frameworks that is Implementation Effectiveness Theoretical Model and Technology Organisation Environment were employed to guide the study by following quantitative method. A survey was used to collect data at government department by means of closed-ended questionnaires, through simple random sampling to produce the results. To measure the relationship between dependent and independent variables data was coded into Statistical Package for Social Science (SPSS) tool for correlations analysis, then conducted regression analysis for constructs contributions. The results show that only three out of the six identified constructs from the research model were accepted to formulate the adoption model. Most previous work done in adoption of BI in public sector has focussed on broader public domain which creates a huge gap in addressing specific requirements or factors influencing adoption of BI in a particular sector. To reduce vagueness and complexity this study investigated factors influencing adoption of BI in South African public social sector Department
\end{abstract}

Keywords: Social Sector, Business Intelligence, Data Warehouse, CGICTPF

\section{Introduction}

In response to development of social protection system public social sector Department has automated some of its business processes to develop system called Nation-al Integrated Social Information Systems (NISIS) that facilitate poverty alleviation program to enhance service delivery through community development, and house-hold profiling services; furthermore, want to increase the scope of 
this system by integrating all business applications in order to drive value and leverage on this information assets. This can be achieved by successfully adopting business intelligence (Kobue, 2010)

\subsection{Background}

The public sector is under enormous pressure as government is rapidly trying to reduce budget deficit and curb spending, this is a very tricky situation in developing countries. The recession, and need to transform the sector and industries for industrial revolution has increased the need for more revenue collection, while making public sector spending cuts a number one priority and yet demand on efficient, effective public service has never been higher (Fildes \& Pidd, 2016)

Having implemented the Governance of ICT Framework in the public service and reporting to the Department of Planning Monitoring and Evaluation very little benefits have been recorded. While poor performance is always reported due to lack of systems, inaccurate and incomplete data. Poor decision making, partial view of business performance, setting and monitoring performance targets, and lack of guidance for BI adoption (Hartley \& Seymour, 2011)

The study aims to contribute to current academic knowledge by assessing National Department within the social sector for inclusive data input coverage towards identifying factors for adoption BI in South African public social sector. Given these drivers the most suitable frameworks to consider all aspects of government operations in fully adopting the business intelligence with all its layers is the Innovation Implementation or Implementation Effectiveness Theoretical Model (IETM) by Klein, et al., (2001), and Technology-Organisations-Environment framework (TOE) developed by Tornatzky, et al., (1990), which is based on three elements of considerations when introducing new system in an organisations, and it would yield better results as it will discover any underlying factors for consideration towards adoption of business intelligence

\subsection{Problem Statement}

As alluded by Adeyelure, Kalema and Bwalya (2016), enterprises in developing countries are facing challenges in accessing real-time intelligent business information for decision making. This study developed a framework for deployment of Mobile Business Intelligence" for SMEs. According to several studies (Shahid, Tavallaee and Shobeiri, 2018; Chaudri, et al.,2011), there is necessity to go down to specific sector for additional study on the acceptance of BI within public sector adoption

According to Ul-Ain, Giovanni and DeLone (2019), little or no research has been done on the adoption of BI, specifically in the public sector domain in developing countries. The study done by Fildes and Pidd, (2016) focused on enhancement of relation between the Small Medium Enterprises (SMEs) in terms of Business Intelligence adoption. Most SMEs rely on strategic business information from government to participate in meaningful economic activities and play supporting role to the government. However, the study was limited to exploratory character and had difficulties with access to the field. Hence this study seeks to address the gap noticed from various literature like ((Ul-Ain et al., 2019; Wowczko, 2016; Paper et al., 2016; Hartley \& Seymour, 2011; Mutanga, 2015; Khan, et al., 2010), by developing a model that will influence the adoption of business intelligence in the South African public social sector department 


\subsection{Major objective / Goal}

To develop a model that will inform the adoption of business intelligence in South African public social sector

\subsubsection{Specific objectives}

1. To identify pertinent factors for adoption of BI South African public social sector

2. To determine the influence of identified factors to adoption Business Intelligence in public social sector

3. To use identified factors to develop a model for adoption of Business Intelligence in South African in public social sector

This study for adoption of business intelligence in public sector was narrowed to give special focus on social sector, where participants views regarding business intelligence were gathered by online questionnaire which gave each participant opportunity to share their knowledge, experience and understanding in using business intelligence. Part One of the questionnaire collected data about the participant demographics. The demographic variable included, gender, age, educational level, years of experience amongst other factors

\section{Literature review}

Mutanga (2015), developed a framework for a Context Based BI solution for Higher Education in South Africa addressing theoretical foundation for information systems research and emphasized context aware business intelligence framework that is suitable for institutional decision making activities within Higher Education. Even though the study was done in public sector it was limited to institutions of higher learning only

Hartley and Seymour (2011), developed a framework for adoption of BI in public sector organisations in South Africa for information systems development assessment based on seven elements i.e. Information; Technology; Process; Objectives and values; Staffing and skills; Management systems and Structures including other resources which are critical for adoption of BI in public sector. It should be noted that there's few literatures available for adoption of BI in public service particularly in South African government

Richards et al., (2014), noted that the adoption of business intelligence for performance management has not been explored until now, which can also be regarded as mixture of management practices and technologies that enable business performance. The study investigated adoption of BI for improved performance management not general adoption of BI and it was carried out in organisations in developed countries

\section{Methodology and approach}

According to Adams and Cox (2008), data collection method refers to a technique that can be used to collect data to address research questions, however it is important that questionnaire is a tool and as such it must be useable, easy to understand, interpret, and complete to increase accuracy of responses; furthermore, structured questionnaires are more suitable for quantitative studies. The study utilized easy 
and understandable structured questionnaires to collect data in answering the research questions. An online Google form tool was utilized for data collection

As stated by Creswell, (2014) there are three research approaches namely; quantitative, qualitative and mixed method which incorporate the two research approaches in a study. The quantitative focuses on analysis of unbiased data and testing the relationship between variables, while quantitative pursues to discover and understand the actual live context in unstructured format. This study followed quantitative research approach to simplify management and assessment of data, the approach allowed the researcher to analyze data numerically using statistical procedures, focusing on dependent and independent variables

\section{Descriptive Analysis of the constructs}

The study extracted and explained descriptive statistics for each construct. The constructs included; management support, financial resource availability, implementation climate, implementation policies and practices, technology, environment and adoption. Each construct had the following statistics extracted, minimum, maximum, mean and skewness.

According to Pallant (2013) descriptive statistics provides a detailed information regarding the distribution and central tendency of the data. It is important to note that the questionnaire used in this study was based on 5-likert scale where 1 represented Strongly Disagree, 2 represented Disagree, 3 represented Neutral, 4 represented Agree and 5 represented Strongly Agree. Table 4.1 below shows the summary of descriptive statistics extracted from SPSS.

Table 4.1: Descriptive Statistics of constructs

\begin{tabular}{|l|r|r|r|r|c|}
\hline Construct & $\mathrm{N}$ & Minimum & Maximum & Mean & Skewness \\
\hline Management Support & 132 & 1 & 5 & 3 & -0.2 \\
\hline Financial Resource Availability & 132 & 1 & 5 & 3 & 0.4 \\
\hline Implementation Climate & 132 & 2 & 5 & 3 & 0.1 \\
\hline Implementation Policies and Practices & 132 & 1 & 5 & 3 & 0.1 \\
\hline Technology & 132 & 1 & 5 & 3 & 0.5 \\
\hline Environment & 132 & 2 & 5 & 4 & -0.3 \\
\hline Adoption & 132 & 1 & 5 & 3 & 0.2 \\
\hline
\end{tabular}

Table 4.1 above shows that management support, financial resource availability, implementation policies and practices, technology and adoption of business intelligence questions had a minimum and maximum option chosen of 1 and 5 respectively, the options that represent Strongly Disagree and Strongly Agree. This means that there were some participants who strongly disagree and others who strongly agree to the questions asked about management support, financial resource availability, implementation policies and practices, technology and adoption of business intelligence. None of the participants strongly disagree to the questions asked about implementation climate and environment. All factors had 5 as the maximum option chosen, meaning that there are some participants that are strongly convinced that the management support, financial resource availability, implementation climate, implementation policies and practices, technology, environment will influence adoption of business intelligence.

Skewness was used to indicate or justify the mean obtained by indicating the alignment of the data around the centre or mean of the data. According to Pallant (2013) a positive skewness means that majority of the data points are distributed towards the left side of the mean, which is the side where there are strongly disagree and disagree options, while a negative skewness means that majority of the data points are scattered towards the right side of the mean which means that majority of the participants 
agree and strongly agree to the questions about the factors. As indicated in table 4.1 management support and environment were the only two factors that had a negative skewness value, meaning that majority of the participants agree and strongly agree to the questions asked about the support rendered by the top management as well as the environment they work in as conducive for adoption and implementation of business intelligence tools.

\subsection{Correlation of the Constructs}

Correlation analysis was conducted after descriptive statistics analysis and Pearson correlation was the method used in this study. The results extracted from SPSS are tabulated in table 4.2.1 below. Correlation analysis is used to describe the relationships between two hypothesised constructs. A Pearson correlation value varies from 0 and a value below 0.3 meaning that the relationship is weak, while a Pearson correlation value between 0.4 and 0.5 means that the relationship is moderately strong and when the Pearson correlation value is over 0.5 it means the strong relationship (Pallant, 2013). Xiaohui et al., (2016) states that a negative Pearson correlation value indicates a proportionally inversed relationship, while a positive value indicates a direct proportional relationship.

Table 4.2.1: Correlation matrix of constructs

\begin{tabular}{|r|r|r|r|r|r|r|r|r|}
\hline & & 1 & 2 & 3 & 4 & 5 & 6 & 7 \\
\hline 1 & Management Support & 1 & & & & & & \\
\hline 2 & $\begin{array}{l}\text { Financial Resource } \\
\text { Availability }\end{array}$ & $.584^{* *}$ & 1 & & & & & \\
\hline 3 & Implementation Climate & $.557^{* *}$ & $.467^{* *}$ & 1 & & & & \\
\hline 4 & $\begin{array}{l}\text { Implementation Policies } \\
\text { and Practices }\end{array}$ & $.522^{* *}$ & $.450^{* *}$ & $.534^{* *}$ & 1 & & & \\
\hline 5 & Technology & $.350^{* *}$ & $.336^{* *}$ & $.394^{* *}$ & $.395^{* *}$ & 1 & & \\
\hline 6 & Environment & $.275^{* *}$ & .104 & $.311^{* *}$ & $.200^{*}$ & $.259^{* *}$ & 1 & \\
\hline 7 & Adoption & $.560^{* *}$ & $.507^{* *}$ & $.621^{* *}$ & $.668^{* *}$ & $.460^{* *}$ & $.260^{* *}$ & 1 \\
\hline & **. Correlation is significant at the 0.01 level (2-tailed). \\
\hline
\end{tabular}

The results in table 4.2.1 above shows that all hypothesised relationships had a positive significant relationship with the dependent variable which is Adoption of business intelligence at 0.01 level as their Pearson correlation values had 2 asterisk. This means there is a direct relationship between adoption and these constructs that have been hypothesised to drive adoption, meaning that as conditions such as top management support, availability of Financial Resource, favourable implementation Climate and department Policies and Practices and availability of compatible technological infrastructure are in place, adoption of business intelligence becomes easy for users and the department as a whole.

Of all the relationships, the relationships between Adoption and the following constructs Implementation Policies and Practices, Implementation Climate, Management Support and Financial Resource Availability had strong relationships as their Pearson correlation values were all above 0.5. The Pearson correlation values between Adoption and all the constructs (Implementation Policies and Practices, Implementation Climate, Management Support, Financial Resource Availability, Technology and Environment) were 0.668, 0.621, 0.560 and 0.507 respectively. The relationship between Adoption and Technology was the only one with values ranging in the moderately strong relationship with a Pearson correlation value of 0.460. Lastly, the relationship between Adoption and Environment was the only relationship which was found to be weak as its Pearson correlation value was found to be 0.260 . 


\subsection{Regression Analysis}

Correlation matrix is enough to investigate the relationship between two constructs only, but when a researcher desires to investigate a collective influence of various factors towards a dependent variable, statistical analysis methods such as Chi square and linear regression should be employed. This study used linear regression from SPSS and the results are shown in table 4.3.1 and 4.3.2

Table 4.3.1: Linear regression model summary

\begin{tabular}{|c|c|c|c|c|c|c|c|c|c|}
\hline \multirow[t]{2}{*}{ Model } & \multirow[t]{2}{*}{$\mathrm{R}$} & \multirow{2}{*}{$\begin{array}{c}\mathrm{R} \\
\text { Square }\end{array}$} & \multirow{2}{*}{$\begin{array}{l}\text { Adjusted } \\
\text { R Square }\end{array}$} & \multirow{2}{*}{$\begin{array}{c}\text { Std. } \\
\text { Error of } \\
\text { the } \\
\text { Estimate }\end{array}$} & \multicolumn{5}{|c|}{ Change Statistics } \\
\hline & & & & & $\begin{array}{c}\mathrm{R} \\
\text { Square } \\
\text { Change }\end{array}$ & $\begin{array}{c}\mathrm{F} \\
\text { Change }\end{array}$ & df1 & df2 & $\begin{array}{l}\text { Sig. } \\
\mathrm{F} \\
\text { Change }\end{array}$ \\
\hline 1 & $.767^{\mathrm{a}}$ & .588 & .568 & .49733 & .588 & 29.747 & 6 & 125 & .000 \\
\hline & $\begin{array}{c}\text { a. } \operatorname{Pr} \\
\text { Implemen }\end{array}$ & $\begin{array}{l}\text { tors: } \\
\text { on Po }\end{array}$ & and $\mathrm{Pr}^{2}$ & Impl & & & & & ology, \\
\hline
\end{tabular}

Table 4.3.1 above shows that the $\mathrm{R}$ square value of the regression model developed by this study is 0.588. However, this study will report on the Adjusted R square as suggested by Pallant, (2013) that once a minor sample is used, the R Square value in the sample inclines to be moderately positive over assessment of the accurate value in the population hence the Adjusted R Square figure rectifies this value to deliver a better estimate of the exact populace value. The sample used in this study was 132 which is not big relative to the total population working in the social sector department.

The Adjusted R Square value was found to be 0.568 , this value means that the following constructs environment, financial-resource-availability, technology, implementation-policies \& practices, implementation-climate and management support collectively predict $56.8 \%$ for the adoption of business intelligence. The model summary shows that $56.8 \%$ of the inconsistency in the dependent variable (Adoption) is clarified by the model (which comprises of the variables for environment, financial-resource-availability, technology, implementation-policies \& practices, implementationclimate and management support). This R-square value is quite high as suggested by Pallant (2013) who noted that, the R-Square value they obtained in their study was $46.8 \%$ and they considered this a reputable result in comparison to some others stated in the journals. Therefore, the R-square we obtained in our study was termed good.

The results indicate that of all the six constructs only three (implementation-policies \& practices, implementation-climate and technology) are found to be meaningfully contribute towards the prediction of adoption of business intelligence at the South African social sector department. Their $\mathrm{p}$ values were found to be $0.00,0.02$ and 0.048 , values which are less than the maximum threshold of 0.05 . The rest of the constructs (management support, financial resource availability and environment) were found to insignificantly contribute towards the prediction of adoption of business intelligence at the South African Social Development department as their values were found to be $0.190,0.121$ and 0.589 respectively, values which are above the maximum threshold value of 0.05 .

Looking at the standardized coefficients column in table 4.3.2 the results show that of the significant constructs, the factor implementation policies and practices contributes $38.1 \%$ towards prediction of adoption of business intelligence at South African social sector department as its Beta value was found to be 0.381 . The second highest contributor towards adoption of business intelligence at the South African social sector department was the factor implementation climate which contributes $24.5 \%$ as its Beta value was found to be 0.245 . The third highest significant contributor towards adoption of business intelligence was the factor technology which contributes $15.8 \%$ as its Beta value was found to be 0.158 .

Table 4.3.2: Individual contribution of constructs 


\begin{tabular}{|c|c|c|c|c|c|c|}
\hline \multirow{2}{*}{\multicolumn{2}{|c|}{ Model }} & \multicolumn{2}{|c|}{$\begin{array}{l}\text { Unstandardized } \\
\text { Coefficients }\end{array}$} & $\begin{array}{l}\text { Standardized } \\
\text { Coefficients }\end{array}$ & \multirow[t]{2}{*}{$\mathrm{t}$} & \multirow[t]{2}{*}{ Sig. } \\
\hline & & $\mathrm{B}$ & Std. Error & Beta & & \\
\hline \multirow{7}{*}{1} & (Constant) & -.040 & .314 & & -.127 & .899 \\
\hline & Management Support & .092 & .070 & .106 & 1.319 & .190 \\
\hline & Financial Resource Availability & .106 & .068 & .116 & 1.560 & .121 \\
\hline & Implementation Climate & .245 & .076 & .248 & 3.227 & .002 \\
\hline & \begin{tabular}{|lll}
$\begin{array}{l}\text { Implementation } \\
\text { Practices }\end{array}$ & Policies and \\
\end{tabular} & .381 & .076 & .370 & 5.022 & .000 \\
\hline & Technology & .158 & .079 & .132 & 2.000 & .048 \\
\hline & Environment & .034 & .063 & .034 & .542 & .589 \\
\hline
\end{tabular}

a. Dependent Variable: Adoption

The regression results above summarises that when one intends to prediction chances of acceptance of BI in the department, the factors to consider are implementation-policies \& practices, implementation climate and technology. The rest of the constructs (management-support, financial-resource-availability and environment) are not useful to consider in the extrapolation for acceptance of Business Intelligence at the public social sector Department in SA

\subsection{Hypothesis Evaluation}

The results in table 4.4.1 were used to evaluate the hypothesis and the results of hypothesis evaluation are shown below. The results indicated that three hypothesis H3, H4 and H5 were accepted while H1, $\mathrm{H} 2$ and $\mathrm{H} 6$ were rejected

Table 4.4.1: Hypothesis evaluation

\begin{tabular}{|c|l|c|c|l|}
\hline $\begin{array}{c}\text { Hypothesis } \\
\text { Code }\end{array}$ & \multicolumn{1}{|c|}{ Hypothesis } & $\begin{array}{c}\text { Beta (P) } \\
\text { value }\end{array}$ & $\begin{array}{c}\text { Evaluation } \\
\text { against } \\
\text { Threshold value } \\
\text { of 0.05 }\end{array}$ & Conclusion \\
\hline H1 & $\begin{array}{l}\text { Management Support will } \\
\text { influence the adoption of BI }\end{array}$ & 0.190 & $\begin{array}{c}\text { Above the } \\
\text { threshold }\end{array}$ & $\begin{array}{l}\text { Hypothesis } \\
\text { rejected }\end{array}$ \\
\hline H2 & $\begin{array}{l}\text { Financial Resources Availability } \\
\text { will influence the adoption of BI }\end{array}$ & 0.121 & $\begin{array}{c}\text { Above the } \\
\text { threshold }\end{array}$ & $\begin{array}{l}\text { Hypothesis } \\
\text { rejected }\end{array}$ \\
\hline H3 & $\begin{array}{l}\text { Implementation Climate influence the } \\
\text { adoption of BI }\end{array}$ & 0.002 & $\begin{array}{l}\text { Below the } \\
\text { threshold }\end{array}$ & $\begin{array}{l}\text { Hypothesis } \\
\text { Accepted }\end{array}$ \\
\hline H4 & $\begin{array}{l}\text { Implementation Policies and } \\
\text { Practices influence the adoption of } \\
\text { BI }\end{array}$ & 0.000 & $\begin{array}{c}\text { Below the } \\
\text { threshold }\end{array}$ & $\begin{array}{l}\text { Hypothesis } \\
\text { Accepted }\end{array}$ \\
\hline H5 & $\begin{array}{l}\text { Technological Characteristics } \\
\text { influence the adoption of BI }\end{array}$ & 0.048 & $\begin{array}{l}\text { Below the } \\
\text { threshold }\end{array}$ & $\begin{array}{l}\text { Hypothesis } \\
\text { Accepted }\end{array}$ \\
\hline H6 & $\begin{array}{l}\text { Environmental Characteristics } \\
\text { influence the adoption of BI }\end{array}$ & 0.589 & $\begin{array}{l}\text { Above the } \\
\text { threshold }\end{array}$ & $\begin{array}{l}\text { Hypothesis } \\
\text { rejected }\end{array}$ \\
\hline
\end{tabular}


The bivariate analysis results indicated that 3 out of 6 hypothesised relations remained supported. The outcomes of the Pearson's correlation showed that all correlations of the hypothesised relationships are statistically substantial. The regression results concluded that Management Support, Financial Resources Availability and Environmental Characteristics have no significant contribution towards adoption of business intelligence. Implementation Climate, Implementation Policies and Technological Characteristics were found to be the only factors that significantly influence adoption of business intelligence

\section{Discussion of findings}

\subsection{Research Question 1}

What are the relevant factors of consideration for adoption BI in South African public social sector?

To answer this question, a thorough literature review was done on related work of adoption of business intelligence in public sector. Many factors were explored in chapter two and were categorized as follows: management-support; financial-resource availability; implementation-climate; implementation-policies \& practices; technological characteristics; and environmental characteristics. However, the factors that have been found to be relevant and specific to the social sector department were the following:

Implementation Climate - BI skills, BI tools, Work quality improvement, Importance of BI, Use of reporting tools, BI usage, and BI reliability; Implementation Policies and Practices - Employees resistance to BI, BI fitting into work environment, and Efficiency; Technological Characteristics Network reliability for BI, VPN access, BI compatibility, and Technologies compatible with business processes

\subsection{Research Question 2}

How do the identified factors influence the adoption of Business Intelligence in South African public social sector?

The influence of the identified factors on the acceptance of Business Intelligence in South African public social sector was tested on SPSS using reliability, correlation and regression analysis which supported some of the identified factors as indicated in question one above. The factors relating to management support, financial re-source availability, and environmental characteristics was established to be irrelevant to the acceptance of Business Intelligence in public social sector department

\subsection{Research Question 3}

How can the identified factors be used to develop a model for adoption of BI in South African public social sector?

After evaluation of the tool and the confirmation of the outcomes which predicted the adoption model for business intelligence in public social sector, of which the outcomes of this study are constant with other researches about adoption of BI with-in public sector. The results of the statistical analysis using SPSS with conclusion from the hypothesis indicated factors with influence to adoption BI in public social sector department as Implementation Climate, Implementation Policies and Practices, and Technological Characteristics 


\subsection{Discussion and implications in relation to hypothesis}

Discussion and implications in relation to the Hypotheses

The six relationships illustrated in Table 5.4.1. above were hypothesized, and are discussed below.

\section{H1: Management Support influence the adoption of Business Intelligence}

The first hypothesis (H1) of the study predicted a positive relationship between the management support and adoption, however its contribution for prediction of adoption of BI in public social sector department has found to be insignificant with $\mathrm{p}$ value of 0.190 which is above maximum threshold of 0.05 and therefore rejected. However, the results of Pearson correlation of constructs for management support is favourable at $.560 * *$ were correlation is significant at 0.01 . As indicated by Huntgeburth et al., (2013), organizational factors such management support, and financial resource availability only moderately influence adoption

\section{H2: Financial Resource Availability influence the adoption of BI}

This hypothesis also predicted a positive relationship between the constructs and adoption were $\mathrm{p}$ value is 0.121 which is above maximum threshold of 0.05 and is therefore rejected. However, the Pearson correlation of constructs results indicated positive value of.507** which is significant at 0.01 . This is also in-line with the out-come of H1 and study by Huntgeburth et al., (2013), were financial resource is found to be insignificant towards adoption of BI in the public sector. This is also supported by Rouhani et al., (2018), were perceived cost associated with adoption of BI was found to have negative insignificant relationship

\section{H3: Implementation Climate influence the adoption of BI}

The third hypothesis of this study predicted a positive relationship between the constructs and adoption with p-value 0.002 which it is significant and below the maxi-mum threshold of 0.05 and it is therefore accepted. This is consistent with other studies were organisations information demanding sectors such as social sector is more expected to adopt IT innovations, which is influenced by essential information and knowledge concentration in the organization. The organization ability to engage and exploit knowledge from numerous sources is becoming a main cause of the technology adoption, meaning employees ability to innovate, gather, maintain, and disseminate knowledge. Thus giving organisations opportunity to reward innovation, commitment and skills (Malladi, 2013)

\section{H4: Implementation Policies and Practices influence adoption of BI}

This hypothesis predicted a positive relationship between the constructs and adoption with a p-value of 0.000 which is also significant and below the maximum threshold of 0.05 , it therefore accepted. Nooradilla et al., (2016) noted that improving the business processes and management enhance the productivity and services. An enabling environment can be created with successful development and implementation of corporate governance policies and framework including willingness by management to sponsor business intelligence structures in the organization. Furthermore, several researches also indicated that the acceptance and application of business intelligence essentially facilitate different aids at individual level and the organization as a whole (Wang, 2014)

H5: Technological Characteristics influence the adoption of BI 
This firth hypothesis predicted a positive relationship with $\mathrm{p}$ value of 0.048 which is less than the maximum threshold of 0.05 and therefore accepted. Ul-Ain et al., (2019), conducted a study on literature review for BI adoption, utilization and success were IS related factors were highlighted. The study hypothesized that IS perspective is critical for adoption meaning technological abilities of business intelligence, quality of systems and information, scalable and bendable IT set-up which support the H5 prediction

\section{H6: Environmental Characteristics influences the adoption of BI}

Hypothesis Environmental Characteristics influence the adoption of BI was rejected with p-value of 0.589 which is above the maximum threshold of 0.05 , the relation-ship between the constructs and adoption predicted positive insignificant including Pearson correlation of $.260 * *$ which is weak. Generally public sector organisations operate in a non-competitive environment which normally reliant on socio-economic, partisan and technical inspirations, consequently, for most of them to prosper they expected to conform to the conviction methods and procedures prevalent within the situation in which they occur including government regulations (Owusu et al., 2017).

Figure 5.4.1: Framework for adoption of BI in South African public social sector Department with all accepted hypothesis depicted below

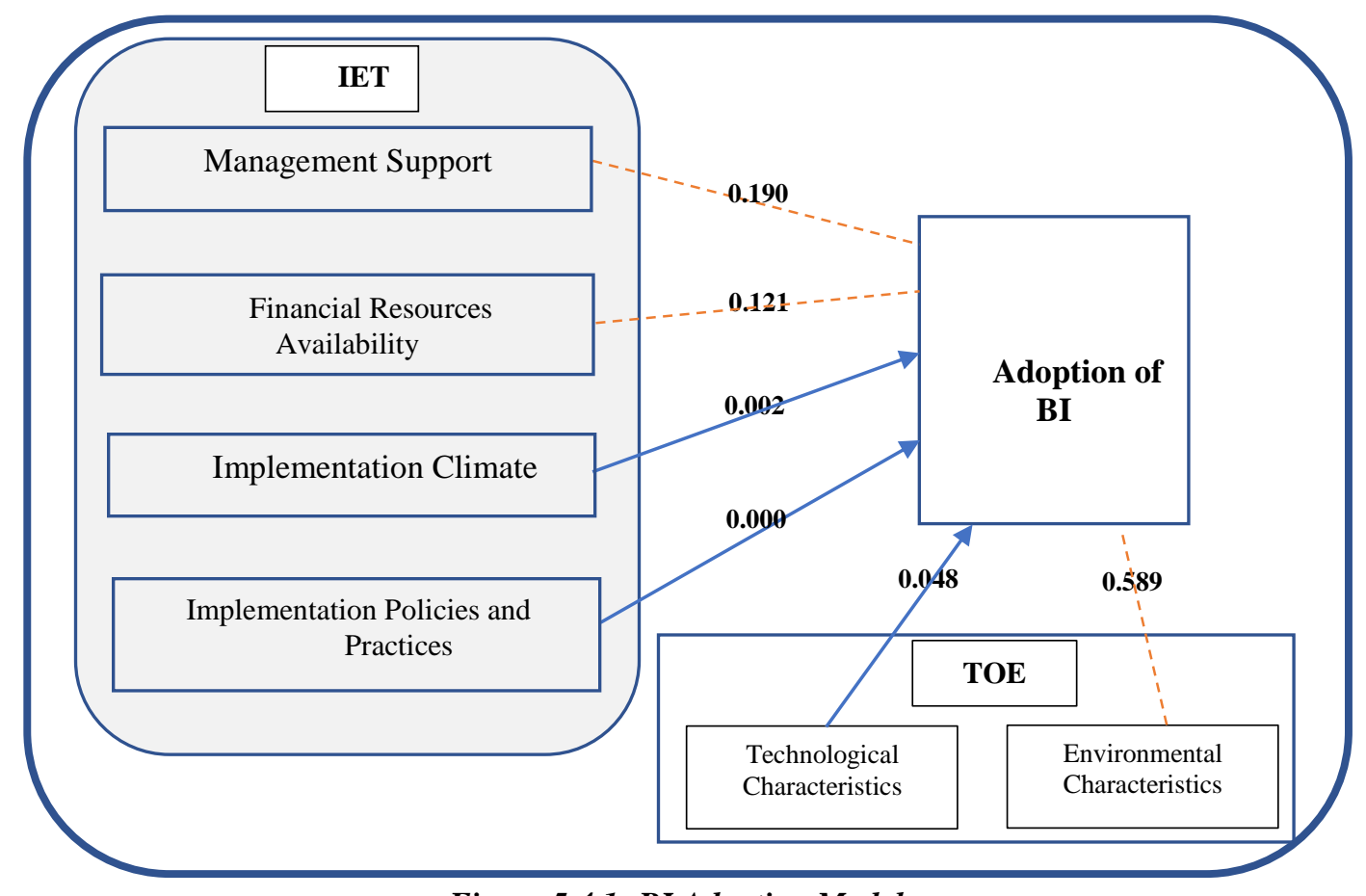

Figure 5.4.1: BI Adoption Model

\subsection{Conclusion}

Having done literature review to confirm the gaps hypothesis were developed with relevant constructs to formulate conceptual model, all necessary preparations for development and testing of data collection tool was done, ethical requirements as per Tshwane University of Technology was followed and permission granted by executive authority to conduct the study, collected data was captured and 
analysed under strict rules of confidentiality. Then actual testing, validating and verification of the data was done using SPSS, the results were also tested for reliability which was $90 \%$ reliable, were adoption model was derived and illustrated on Figure 5.4.1 above for adoption of Business Intelligence at the South African public social-sector Department

\section{References}

1. Fildes, R. and Pidd, M. (no date) 'The Benefits of Analytics in the Public Sector'.

2. Huntgeburth et al. (2013) 'Increasing the Adoption of E-Procurement Services at the Municipal Level', e-Service Journal, 8(3), p. 3. doi: 10.2979/eservicej.8.3.3.

3. Hartley, K. \& Seymour, L. F., 2011. Towards a framework for adoption of Business Intelligence in public sector organisations: the case of South Africa. SAICSIT'11, pp. 116-122.

4. Hartley, M. K. \& Seymour, L. F., 2015. Business Intelligence in South African public sector organisations. Nungwi, Steyn, J.,Van Belle, J.P. (Eds), pp. 249-265.

5. Khan, A. M. A., Amin, N. \& Lambrou, N., 2010. Drivers and Barriers to Business Intelligence adoption: A Case of Pakistan. Abu Dhabi, EMCIS2010.

6. Klein, K., Conn, A. \& Sorra, J., 2001. Implementing computerized technology: an organizational analysis. Journal of Applied Psychology, Vol.86(No.5), pp. 811-824.

7. Kobue, J., 2010. Department of Social Development. [Online] Available at: [Accessed 07 July 2017].

8. Malladi, S. (2013) 'Adoption of Business Intelligence \& Analytics in Organizations - An Empirical Study of Antecedents', AMCIS 2013 Proceedings, 2016, pp. 1-11. Available at: http://aisel.aisnet.org/amcis2013/BusinessIntelligence/GeneralPresentations/3.

9. Mutanga, A., 2015. A Context-Based Business Intelligence Solution for Souith African Higher Education. Journal of Industrial and Intelligent Information, Vol.3(2), pp. 119-125.

10. Nooradilla, A. et al. (2016) 'Business Intelligence Readiness Factors for Higher Education Institution', Journal of Theoretical and Applied Information Technology, 15(1), pp. 174-181. Available at: www.jatit.org.

11. Owusu, A. et al. (2017) 'Determinants of Business Intelligence Systems Adoption In Developing Countries: An Empirical Analysis From Ghanaian Banks', Journal of Internet Banking and Commerce, 22(22S8). Available at: http://www.icommercecentral.com/openaccess/determinants-of-business-intelligence-systems-adoption-in-developing-countries-anempirical-analysis-from-ghanaian-banks.pdf.

12. Pallant, J., 2013. SPSS Survival Mnaual. 5th Edition ed. Backshire England: McGraw Hill.

13. Paper, W. et al. (2016) 'Wp-Analytics-Public-Sector-1639Uk1111.Pdf', SAJIM: South African Journal of Information Management. Elsevier Masson SAS, 15(1), pp. 1-18. doi: 10.1007/978-1-4471-4866-1_1.

14. Richards, G., Yeoh, W. \& Chong, A. Y. L., 2014. An Impirical Study of Business Intelligence impact on Corporate Performance Management. Chengbu, AIS eLiberty.

15. Rouhani, S. et al. (2018) 'Business Intelligence Systems Adoption Model', Journal of Organizational and End User Computing, 30(2), pp. 43-70. doi: 10.4018/JOEUC.2018040103.

16. Tornatzky, L. G., Fleischer, M. \& Chakrabarti, A. K., 1990. The process of technological innovation. Lexington, Mass: Lexington Books.

17. Ul-Ain, N. et al. (2019) 'Business intelligence system adoption, utilization and success-A systematic literature review', Scholarspace.Manoa.Hawaii.Edu, 6, pp. 5888-5897. Available at: https://scholarspace.manoa.hawaii.edu/handle/10125/60024. 
18. Wang, H. C. (2014) 'Distinguishing the adoption of business intelligence systems from their implementation: The role of managers personality profiles', Behaviour and Information Technology, 33(10), pp. 1082-1092. doi: 10.1080/0144929X.2013.869260.

19. Wowczko, I. (2016) 'Business Intelligence in Government Driven Environment Institute of Technology’, 9(1), pp. 1107-1111.

20. Xiaohui, Y. et al. (2016) 'PARTIAL LEAST SQUARE S (PLS - SEM) - Regression and Structural Equation Models', Politeness and Audience Response in Chinese-English Subtitling, (March 2014), pp. 39-49. doi: 10.3726/978-3-0353-0280-6/8. 